\title{
Increase in Salivary Oxytocin Levels in Mothers After Tactile Contact Between Adiaper-like Nonwoven Sheet With Large Projectionsand the Palm: A Pilot Study
}

Takashi Sakamoto ( $\sim$ sakamoto.takashi@kao.com )

aSensory Science Research, Kao Corporation, 2606 Akabane, Ichikaimachi, Haga, Tochigi, Japan

Sayaka Izumori

Kao Corporation

Mina Tomita

Kao Corporation

Yuko Fukuda

Kao Corporation

Yasuyuki Okuda

Kao Corporation

Naoko Saito

Kao Corporation

Junji Nakamura

Kao Corporation

Research note

Keywords: Palm, Oxytocin, Texture, Diaper, Mother, Non-C type fibers

Posted Date: August 13th, 2020

DOI: https://doi.org/10.21203/rs.3.rs-52180/v1

License: (c) (1) This work is licensed under a Creative Commons Attribution 4.0 International License.

Read Full License 


\section{Abstract}

\section{Objective}

The aim of this pilot study was to investigate whether or not tactile contact between a diaper-like nonwoven sheet with specific physical characteristics and the palm of the hand would increase the maternal level ofoxytocinwhich is one of the neuropeptides promoting formation of the mother-infant bond.

\section{Results}

Ten healthy non-breastfeeding Japanese mothers were enrolled in this pilot study. We prepared diaper-like nonwoven sheets with large or small projections. Physical indices related to softness and fluffiness were higher in the sheet with large projections than in the sheet with small projections. Salivary oxytocin levels in the motherswere increasedafter tactile contact with thesheet with large projections, but not after contact with the sheet with small projections. This pilot study suggests that maternal oxytocin levels are increased by tactile contact between a soft and fluffy diaper sheet and the palm.

\section{Introduction}

Mother-infant interaction behavior evokes physiological and cognitive responses in mothers and infants, and is associated with formation of a mutual bond [1-5]. Mothers interact with their infants in a variety of daily activities, including diapering, feeding, bathing, and playing. Diapering behavior in particular is a daily routine that involves intuitive parenting behavior. This activity is one of the most important interactions needed to establish a reciprocal relationship between a mother and infant [6-8].

Enhancement of the mother-infant relationship is related to the level of oxytocin, which is one of the functional neuropeptides synthesized in the brain [9-14]. It has been reported that the central oxytocin level shows a significant positive correlation with the peripheral oxytocin level [15-17]. Furthermore, salivary OT (sOT) levels in mothers are related to physical proximity to their infants and to the duration of mother-to-infant gaze $[12,18]$. These suggest that an increase in the peripheral maternal oxytocin level is associated with improvement in the quality of the mother-infant relationship. Oxytocin is released in response to a variety of sensory inputs [19], in particular, tactile sensation [11, 19]. Touch is mainly perceived by the C-low-threshold mechanoreceptive (CT) fibers which project to the hairy skin, and the non-C type fibers which innervate not only the hairy skin but also the glabrous skin, indicating that touch in the glabrous skin of the palm is perceived by the non-C type fibers [20-33]. Mother-infant skin-to-skin contact, which could activate the CT fibers, increases peripheral levels of oxytocin [34, 35]. Moreover, foot massage which could activate both types of fibers promotes a pleasurable sensation, and increases peripheral oxytocin levels [29]. Therefore, it is plausible that activation of the non-C type fibers also upregulates oxytocin levels. However, this hypothesis has not been well investigated. 
We hypothesized that activation of the non-C type fibers by tactile contact between the glabrous skin of the palm and a diaper with specific physical characteristics could increase maternal peripheral oxytocin levels with accompanying cognitive and psychological changes. To examine this possibility, we prepared a diaper-like nonwoven sheet with large projections (LP sheet) and a sheet with small projections (SP sheet). We expected that the physical characteristic values would be different between the two types of sheet. Additionally, we investigated the changes in SOT levels after mothers touched the sheets with both palms, and the differences in perceived pleasantness value between the different types of sheets.

\section{Material And Methods}

\section{Sp And Lp Sheets}

Top views of the SP and LP sheet are shown in Additional file 1. A nonwoven sheet was processed into small or large projections and laminated with a flat air-through nonwoven sheet. To construct the diaperlike shape, the nonwoven sheets with large or small projections were glued with substructural components composed of absorbent waterproof film and an outer nonwoven sheet.

\section{Measurement of physical characteristic values of the SP and LP sheets}

The convex parts of the cut sections of the SP and LP sheets were determined by observation under a microscope (VHX-1000, KEYENCE, Osaka, Japan) at a magnification of 10-100x. Under microscopic observation, the length was measured along the upper and bottom surfaces as shown in Additional file 2, and the ratio of the upper length to the bottom length was calculated. The workload compression (WC), which indicates the compression energy per $1 \mathrm{~cm}^{2}$, was measured in each sheet at a velocity of $0.02 \mathrm{~cm} / \mathrm{sec}$ and a maximum pressure of $50 \mathrm{~g} / \mathrm{cm}^{2}$ over an area of $2.0 \mathrm{~cm}^{2}$ using the KESFB4-AUTO-A surface tester (Kato Tech, Kyoto, Japan).

\section{Study Participants}

The study participants were 10 healthy non-breastfeeding Japanese mothers aged 30-49 years who were employees at Kao Corporation. The participants were instructed not to eat or drink (except for water), brush their teeth, smoke, or use hand care products for at least $60 \mathrm{~min}$ prior to the measurements.

\section{Study Design}

Three conditions were randomly tested between 9:00 am and noon for each participant: (1) resting; (2) touching the SP sheet; and (3) touching the LP sheet. The minimum interval between the trials was 1 day. The participants were asked to wash their hands using hand soap. After resting for 5 min, the participants were asked to rinse the mouth with bottled water and spit whole saliva into a sterile plastic tube for 10 min. The participants were then asked to stroke their both palms over the SP or LP sheet for $30 \mathrm{sec}$ 
five times at intervals of $30 \mathrm{sec}$, or to rest for $5 \mathrm{~min}$. Whole saliva was collected just after and $30 \mathrm{~min}$ after touching or resting for $10 \mathrm{~min}$. The whole saliva was stored at $-80^{\circ} \mathrm{C}$ until further analysis. Perceived pleasantness was rated using a $10-\mathrm{cm}$ visual analog scale just after touching or resting. On another day after the three trials, the participants were asked to touch the SP and LP sheets, and rate the softness and fluffiness scores.

\section{Measurement Of Salivary Oxytocin And Cortisol Levels}

The sOT and salivary cortisol (sCORT) concentrations were quantified using a commercial kit (sOT: ADI900-153, Enzo Life Sciences, Plymouth Meeting PA, USA; sCORT: 1-1102, Salimetrics Inc., Carlsbad, CA, USA). Saliva samples were extracted for measurement of SOT concentration following the manufacturer's protocol $[36,37]$. The SOT and SCORT concentrations were assessed in duplicate and calculated using the Epoch2 microplate reader (BioTek Instruments, Inc., Winooski, VT, USA) according to the relevant standard curves. The intra-assay coefficients of variation for SOT and SCORT measurements were $13.8 \%$ and $3.1 \%$, respectively. The salivary total protein concentration was determined using a standard bovine serum albumin curve (5000002JA, Bio-Rad Laboratories, Inc., Hercules, CA, USA).

\section{Statistical analysis}

The statistical analyses were performed using GraphPad Prism version 6.0 (Graphpad Software Inc., La Jolla, CA, USA). One-way analysis of variance with Dunnett's and Tukey's post hoc tests were performed to compare the multiple groups.

\section{Results}

\section{Physical Characteristic Values Of Sheets}

First, we measured two physical characteristic values related to softness and fluffiness, i.e., the upper/bottom length ratio of the convex parts and the WC value in each sheet [38,39]. Both indices were higher in the LP sheet than in the SP sheet (Table 1). Furthermore, the softness and fluffiness evaluation scores for the LP sheet were slightly but not significantly higher than those for the SP sheet (Supplementary File 3).

Table 1 Physical characteristic values of the SP and LP sheets

\begin{tabular}{|lll|}
\hline Sheet & Upper/bottom length ratio & WC $\left(\mathrm{gf} \cdot \mathrm{cm} / \mathrm{cm}^{2}\right)$ \\
\hline $\mathrm{SP}$ & 1.1 & 0.20 \\
$\mathrm{LP}$ & 1.5 & 0.42 \\
\hline
\end{tabular}


LP sheet: diaper-like nonwoven sheet with large projections; SP: diaper-like nonwoven sheet with small projections; WC:workload compression.

\section{Change in salivary oxytocin levels after resting and touching sheets}

We calculated the amount of sOT ( $\mathrm{pg} / \mathrm{mg}$ protein) by dividing the sOT concentration by the total protein concentration in each saliva sample, given that psychological stress influences the salivary flow rate and total protein concentration $[40,41]$. The amounts of sOT at 30-40 min $\left(\mathrm{sOT}_{30}-40\right)$ after touching the LP sheet were significantly increased $(p<0.05)$, and those at $0-10 \mathrm{~min}\left(\mathrm{sOT}_{0}-10\right)$ approached statistical significance $(p=0.0609)$ compared with before touching (Fig. 1). However, there were no significant differences in the conditions of resting and touching the SP sheet (Fig. 1). Even without normalization using the total salivary protein concentration, the concentration of $\mathrm{sOT}_{30-40}$ after touching the LP sheet was significantly increased $(p<0.05)$ compared with before touching (Additional file 4 ). There was no significant difference in the sCORT concentration under any condition (Additional file 5).

Perceived Pleasantness Values After Resting And Touching The Sheets

The perceived pleasantness values just after touching the SP and LP sheets were significantly higher than those after resting $(p<0.05$, Fig. 2$)$. However, there was no significant difference between the SP and LP sheet $(p=0.9233$, Fig. 2).

\section{Discussion}

We have investigated the changes in maternal sOT levels after tactile contact between a nonwoven sheet and the palm which is innervated by the non-C type fibers. We prepared the two types of diaper-like nonwoven sheets (LP and SP sheet). The physical indices related to softness and fluffiness were higher in the LP sheet. Furthermore, we found that SOT levels were significantly increased after touching the LP sheet with the palms, but not after touching the SP sheet or resting. It has been suggested that activation of the CT fibers increases maternal oxytocin levels $[34,35]$. To the best of our knowledge, this pilot study is the first report suggesting an increase in peripheral oxytocin levels after tactile contact between a soft and fluffy diaper sheet and the palm innervated by the non-C type fibers.

Maternal sOT levels were significantly increased after touching the LP sheet with the palm, but not after touching the SP sheet. The physical indices related to softness and fluffiness for the LP sheet were greater than those for the SP sheet. Furthermore, the perceived pleasantness values after touching both sheets were significantly higher than those after resting, but were not different between the two types of sheets. It has been suggested that greater activation of the CT fibers arouses a more pronounced feeling of pleasure, and a greater increase in oxytocin levels $[34,42,43]$. Therefore, this pilot study implies that perception of softness and fluffiness could have an important role in inducing an increase in oxytocin levels via the non-C type fibers.

In this study, the $\mathrm{SOT}_{30-40}$ levels after touching the LP sheet were significantly increased compared with before touching, but there were no significant differences in the $\mathrm{sOT}_{0-10}$ levels. Previous research 
suggests that tactile stimulation arousing feelings of softness and fluffiness activates the mechanoreceptors innervated by the non-C type fibers in the glabrous skin of the palm, and induces an increase in the central oxytocin level by activation of oxytocin neurons in the brain followed by secretion in the periphery $[26,44,45]$. It has been reported that intranasal administration of oxytocin, which increases the central oxytocin level, increases peripheral oxytocin levels at $30 \mathrm{~min}$ after administration in humans $[46,47]$. These observations imply that the increase of the amount of $\mathrm{sOT}_{30-40}$ after touching the LP sheet might be attributed to increased central oxytocin level after activation of the non-C type fibers in the palm.

In summary, we have demonstrated that maternal sOT levels were increased after tactile contact between diaper-like nonwoven sheet with large projections and the palm innervated by the non- $C$ type fibers. This pilot study could provide a new approach to increase maternal oxytocin levels by tactile stimulation during diapering behavior. This strategy might have the potential to improve the quality of the motherinfant relationship.

\section{Limitations}

This pilot study has some limitations. First, the sample size was small, and all study participants were recruited from the author's institution. Although our participants did not have expertise in the field of neuroscience, it would be necessary to recruit a large number of unrelated participants for further study. Second, texture evaluation of the sheets and saliva collection for measurement of oxytocin level were performed on different days, which might account for the lack of a significant difference in the texture evaluation scores between the two types of sheets. Further studies would be required to clarify the effect of texture impression on changes in maternal oxytocin levels. Third, the influence of the menstrual cycle on the fluctuations in SOT levels may have been overlooked in this pilot study. However, fluctuations in the peripheral oxytocin levels over the course of the menstrual cycle are controversial [48-50]. In our study, the amounts of sOT before resting, touching the SP sheet, and touching the LP sheet were not significantly different $(F[2,23]=1.490, p=0.2463$, one-way analysis of variance with Tukey's post hoc test). Therefore, although we did not confirm the phases of menstrual cycle of the participants, the influence of fluctuations in SOT levels before resting and touching the sheets might be ignored in this study.

\section{List Of Abbreviation}

CT fibers, C-low-threshold mechanoreceptive fibers

LP sheet, diaper-like nonwoven sheet with large projections

SP sheet, diaper-like nonwoven sheet with small projections

sCORT, salivary cortisol 
sOT, salivary oxytocin

$\mathrm{sOT}_{0-10}$, salivary oxytocin at 0-10 min after touching the sheet or resting

$\mathrm{sOT}_{30-40}$, salivary oxytocin at 30-40 min after touching the sheet or resting

WC, workload compression

\section{Declarations}

\section{Ethics approval and consent to participate}

This study was approved by the Human Research Ethics Committee at Kao Corporation (\#T093-180123). Written informed consent was obtained from all study participantsat the time of enrolment in the study.

\section{Consent for publication}

All participants provided written informed consent for publication of thisreport.

\section{Availability of data and materials}

All data generated or analyzed during this study are included in this published article and its supplementary information files.

\section{Competing interests}

All authors are employees of Kao Corporation.

\section{Funding}

Kao Corporation funded this research.

\section{Author contributions}

$\mathrm{TS}, \mathrm{SI}$, and MT designed the experiments, performed the majority of the experiments, analyzed the data, and participated in writing and editing the manuscript. YF, YO, and NS designed the experiments, analyzed the data, and participated in editing the manuscript. JN designed the experiments, analyzed the data, participated in editing the manuscript, and oversaw all aspects of the study.

\section{Acknowledgements}

Not applicable.

\section{References}


1. Sroufe LA. Attachment and development: a prospective, longitudinal study from birth to adulthood. Attach Hum Dev. 2005;7(4):349-67.

2. Mäntymaa M. Early mother-infant interaction. Printed Dissertation. Acta Universitatis Tamperensis. 2016.

3. Lyons-Ruth K, Jacobvitz D. Attachment disorganization: genetic factors, parenting contexts and developmental transformations from infancy to adulthood. In: J. Cassidy, P.R. Shaver, editors, Handbook of Attachment: Theory, Research, and Clinical Applications, second edition. Guilford Press, New York; 2008. p. 666 - 97.

4. Thompson RA. Early attachment and later development: familiar questions, new answers. in: J. Cassidy, P.R. Shaver, editors, Handbook of Attachment: Theory, Research, and Clinical Applications, second edition. Guilford Press, New York; 2008. p. 348 - 65.

5. Butruille L, Blouin A, Jonckheere JD, Mur S, Margez T, Rakza T, Storme L. Impact of skin-to-skin contact on the autonomic nervous system in the preterm infant and his mother. Infant Behav Dev. 2017;49:83-6.

6. Montague DR, Walker-Andrews AS. Mothers, fathers, and infants: the role of person familiarity and parental involvement in infants' perception of emotion expressions. Child Dev. 2002;73:1339-52.

7. Addessi AR. The musical dimension of daily routines with under-four children during diaper change, bedtime and free-play. Early Child Dev Care. 2009;179(6):747-68.

8. Rime J, Tissot H, Favez N, Watson M, Stadlmayr W. The diaper change play: validation of a new observational assessment tool for early triadic family interactions in the first month postpartum. Front Psychol. 2018;9:497.

9. Fineberg SK, Ross DA. Oxytocin and the social brain. Biol Psychiatry. 2017;81(3):e19-21.

10. Feldman R, Weller A, Zagoory-Sharon O, Levine A. Evidence for a neuroendocrinological foundation of human affiliation: plasma oxytocin levels across pregnancy and the postpartum period predict mother-infant bonding. Psychol Sci. 2007;18(11):965-70.

11. Feldman R, Gordon I, Schneiderman I, Weisman O, Zagoory-Sharon O. Natural variations in maternal and paternal care are associated with systematic changes in oxytocin following parent-infant contact. Psychoneuroendocrinology. 2010;35(8):1133-41.

12. Strathearn L, Fonagy P, Amico J, Montague PR. Adult attachment predicts maternal brain and oxytocin response to infant cues. Neuropsychopharmacology. 2009;34(13):2655-66.

13. Gordon I, Zagoory-Sharon O, Leckman JF, Feldman R. Oxytocin and the development of parenting in humans. Biol Psychiatry. 2010;68(4):377-82.

14. Insel TR. The challenge of translation in social neuroscience: a review of oxytocin, vasopressin, and affiliative behavior. Neuron. 2010;65(6):768-79.

15. Carter CS, Pournajafi-Nazarloo H, Kramer KM, Ziegler TE, White-Traut R, Bello D, et al. Oxytocin: behavioral associations and potential as a salivary biomarker. Ann NY Acad Sci. 2007;1098:312-22. 
16. Valstad M, Alvares GA, Egknud M, Matziorinis AM, Andreassen OA, Westlye LT, et al. The correlation between central and peripheral oxytocin concentrations: a systematic review and meta-analysis. Neurosci Biobehav Rev. 2017;78:117-24.

17. Martin J, Kagerbauer SM, Gempt J, Podtschaske A, Hapfelmeier A, Schneider G. Oxytocin levels in saliva correlate better than plasma levels with concentrations in the cerebrospinal fluid of patients in neurocritical care. J Neuroendocrinol. 2018; e12596.

18. Kim S, Fonagy P, Koos O, Dorsett K, Strathearn L. Maternal oxytocin response predicts mother-toinfant gaze. Brain Res. 2014;1580:133-42.

19. Nagasawa M, Okabe S, Mogi K, Kikusui T. Oxytocin and mutual communication in mother-infant bonding. Front Hum Neurosci. 2012; 6(31).

20. Kumazawa T, Perl ER. Primate cutaneous sensory units with unmyelinated (C) afferent fibers. J Neurophysiol. 1977;40(6):1325-38.

21. Johansson RS, Vallbo AB. Tactile sensibility in the human hand: relative and absolute densities of four types of mechanoreceptive units in glabrous skin. J Physiol (Lond). 1979;286:283-300.

22. Vallbo A, Olausson $H$, Wessberg J, Norrsell U. A system of unmyelinated afferents for innocuous mechanoreception in the human skin. Brain Res. 1993;628(1-2):301-4.

23. Vallbo $A B$, Olausson $H$, Wessberg $\mathrm{J}$. Unmyelinated afferents constitute a second system coding tactile stimuli of the human hairy skin. J Neurophysiol. 1999;81(6):2753-63.

24. Johnson KO, Yoshioka T, Vega-Bermudez F. Tactile functions of mechanoreceptive afferents innervating the hand. J Clin Neurophysiol. 2000;17(6):539-58.

25. Light AR, Perl ER. Unmyelinated afferent fibers are not only for pain anymore. J Comp Neurol. 2003;461(2):137-9.

26. Delmas P, Hao J, Rodat-Despoix L. Molecular mechanisms of mechanotransduction in mammalian sensory neurons. Nat Rev Neurosci. 2011;12(3):139-53.

27. Ohlsson A, Jacobs SE. NIDCAP: a systematic review and meta-analyses of randomized controlled trials. Pediatrics. 2013;131(3):e881-93.

28. Maitre NL, Key AP, Chorna OD, Slaughter JC, Matusz PJ, Wallace MT, et al. The dual nature of earlylife experience on somatosensory processing in the human infant brain. Curr Biol. 2017;27(7):104854.

29. Li Q, Becker B, Wernicke J, Chen Y, Zhang Y, Li R, et al. Foot massage evokes oxytocin release and activation of orbitofrontal cortex and superior temporal sulcus. Psychoneuroendocrinology. 2019;101:193-203.

30. McGlone F, Wessberg J, Olausson H. Discriminative and affective touch: sensing and feeling. Neuron. 2014;82(4):737-55.

31. Johansson RS, Westling G. Signals in tactile afferents from the fingers eliciting adaptive motor responses during precision grip. Exp Brain Res. 1987;66(1):141-54. 
32. Ackerley R, Backlund-Wasling H, Liljencrantz J, Olausson H, Johnson RD, Wessberg J. Human Ctactile afferents are tuned to the temperature of a skin-stroking caress. J Neurosci. 2014;34(3):287983.

33. Croy I, Sehlstedt I, Wasling HB, Ackerley R, Olausson H. Gentle touch perception: From early childhood to adolescence. Dev Cogn Neurosci. 2019;35:81-6.

34. Cong X, Ludington-Hoe SM, Hussain N, Cusson RM, Walsh S, Vazquez V, et al. Parental oxytocin responses during skin-to-skin contact in pre-term infants. Early Hum Dev. 2015;91(7):401-6.

35. Vittner D, McGrath J, Robinson J, Lawhon G, Cusson R, Eisenfeld L, et al. Increase in oxytocin from skin-to-skin contact enhances development of parent-infant relationship. Biol Res Nurs. 2018;20(1):54-62.

36. Szeto A, McCabe PM, Nation DA, Tabak BA, Rossetti MA, McCullough ME, et al. Evaluation of enzyme immunoassay and radioimmunoassay methods for the measurement of plasma oxytocin. Psychosom Med. 2011;73(5):393-400.

37. Ide $M$, Wada M. Salivary oxytocin concentration associates with the subjective feeling of body ownership during the rubber hand illusion. Front Hum Neurosci. 2017;11:166.

38. Elder HM, Fisher S, Armstrong K, Hutchison G. 5-Fabric softness, handle, and compression. J Text Inst. 1984;75(1):37-46.

39. Hu J, Ding X, Zeng X, Koehl L. Effect of instantaneous compression responses of fabric on tactile textures. Indian J Fibre Text Res. 2009;34:52-8.

40. Matos-Gomes N, Katsurayama M, Makimoto FH, Santana LL, Paredes-Garcia E, Becker MA, et al. Psychological stress and its influence on salivary flow rate, total protein concentration and $\lg A$, IgG and IgM titers. Neuroimmunomodulation. 2010;17(6):396-404.

41. Takai N, Yamaguchi M, Aragaki T, Eto K, Uchihashi K, Nishikawa Y. Effect of psychological stress on the salivary cortisol and amylase levels in healthy young adults. Arch Oral Biol. 2004;49(12):963-8.

42. Löken LS, Wessberg J, Morrison I, McGlone F, Olausson H. Coding of pleasant touch by unmyelinated afferents in humans. Nat Neurosci. 2009;12(5):547-8.

43. Walker SC, Trotter PD, Swaney WT, Marshall A, Mcglone FP. C-tactile afferents: cutaneous mediators of oxytocin release during affiliative tactile interactions? Neuropeptides. 2017;64:27-38.

44. Neumann ID. Stimuli and consequences of dendritic release of oxytocin within the brain. Biochem Soc Trans. 2007;35(5):1252-7.

45. Hu J, Zhao Q, Jiang R, Wang R, Ding X. Responses of cutaneous mechanoreceptors within fingerpad to stimulus information for tactile softness sensation of materials. Cogn Neurodyn. 2013;7(5):4417.

46. Striepens N, Kendrick KM, Hanking V, Landgraf R, Wüllner U, Maier W, et al. Elevated cerebrospinal fluid and blood concentrations of oxytocin following its intranasal administration in humans. Sci Rep. 2013;3:3440. 
47. Gossen A, Hahn A, Westphal L, Prinz S, Schultz RT, Gründer G, et al. Oxytocin plasma concentrations after single intranasal oxytocin administration - a study in healthy men. Neuropeptides. 2012;46(5):211-5.

48. Altemus M, Roca C, Galliven E, Romanos C, Deuster P. Increased vasopressin and adrenocorticotropin responses to stress in the midluteal phase of the menstrual cycle. J Clin Endocrinol Metab. 2001;86(6):2525-30.

49. Salonia A, Nappi RE, Pontillo M, Daverio R, Smeraldi A, Briganti A, et al. Menstrual cycle-related changes in plasma oxytocin are relevant to normal sexual function in healthy women. Horm Behav. 2005;47(2):164-9.

50. Rubin LH, Carter CS, Drogos LL, Pournajafi-Nazarloo H, Sweeney JA, Maki PM. Effects of sex, menstrual cycle phase, and endogenous hormones on cognition in schizophrenia. Schizophr Res. $2015 ; 166(1-3): 269-75$.

\section{Figures}

\section{Fig 1}

Resting

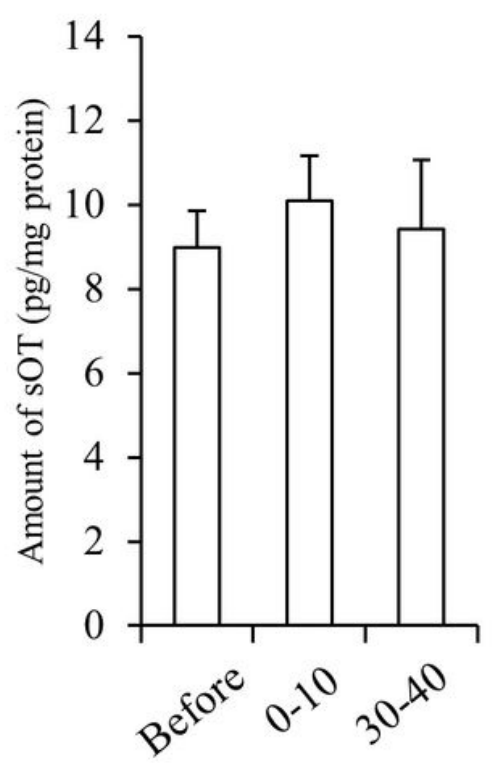

Touching SP sheet

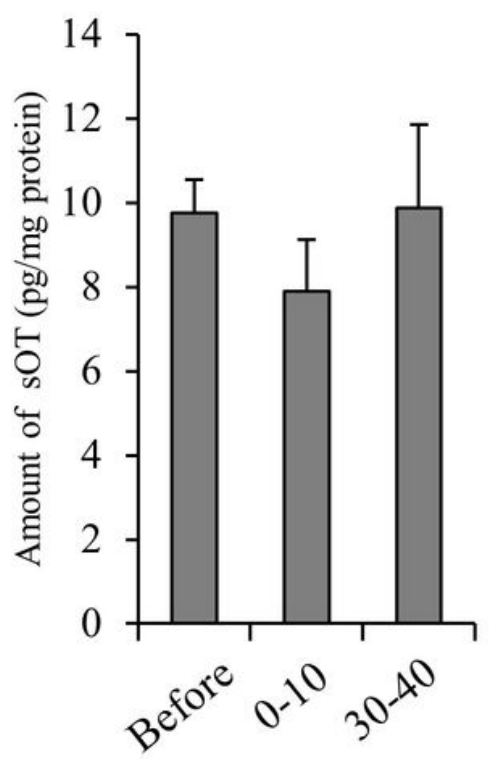

Touching LP sheet

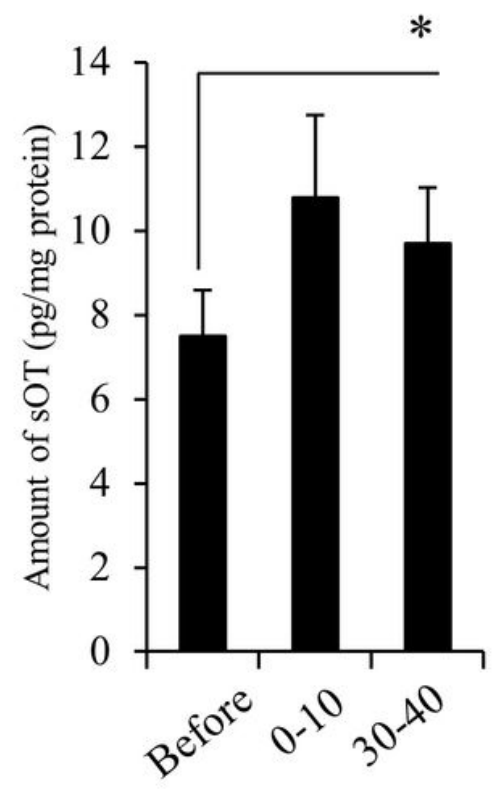

Time after resting or touching sheet $(\mathrm{min})$

Figure 1 
Salivary oxytocin levels before and after resting and touching thesheets. All data are presented as the mean \pm standard error of the mean $(n=8-9)$. The data were analyzed using one-way analysis of variance with Dunnett's posthoc test(rest $[F(1.815,14.52)=0.3478, p=0.6919$; before: $8.98 \pm 0.86 \mathrm{pg} / \mathrm{mg}$ protein; 0-10 min: $10.09 \pm 1.06 \mathrm{pg} / \mathrm{mg}$ protein; $30-40 \mathrm{~min}: 9.42 \pm 1.64 \mathrm{pg} / \mathrm{mg}$ protein, $\mathrm{n}=9]$, SP sheet [F (1.973, $13.81)=0.6746, p=0.5235$; before: $9.74 \pm 0.81 \mathrm{pg} / \mathrm{mg}$ protein; $0-10 \mathrm{~min}: 7.90 \pm 1.22 \mathrm{pg} / \mathrm{mg}$ protein; $30-$ 40 min: $9.87 \pm 1.98 \mathrm{pg} / \mathrm{mg}$ protein, $n=8]$, LP sheet $[F(1.233,9.861)=5.963, p<0.05$; before: $7.49 \pm 1.08$ $\mathrm{pg} / \mathrm{mg}$ protein; $0-10 \mathrm{~min}: 10.79 \pm 1.96 \mathrm{pg} / \mathrm{mg}$ protein; $30-40 \mathrm{~min}: 9.69 \pm 1.32 \mathrm{pg} / \mathrm{mg}$ protein, $\mathrm{n}=9 \mathrm{]}) .{ }^{\star} \mathrm{p}<$ 0.05 vs. before resting or touching. LP sheet:diaper-like nonwoven sheet with large projections; sOT: salivary oxytocin; SP sheet:diaper-like nonwoven sheet with small projections. 
Fig 2

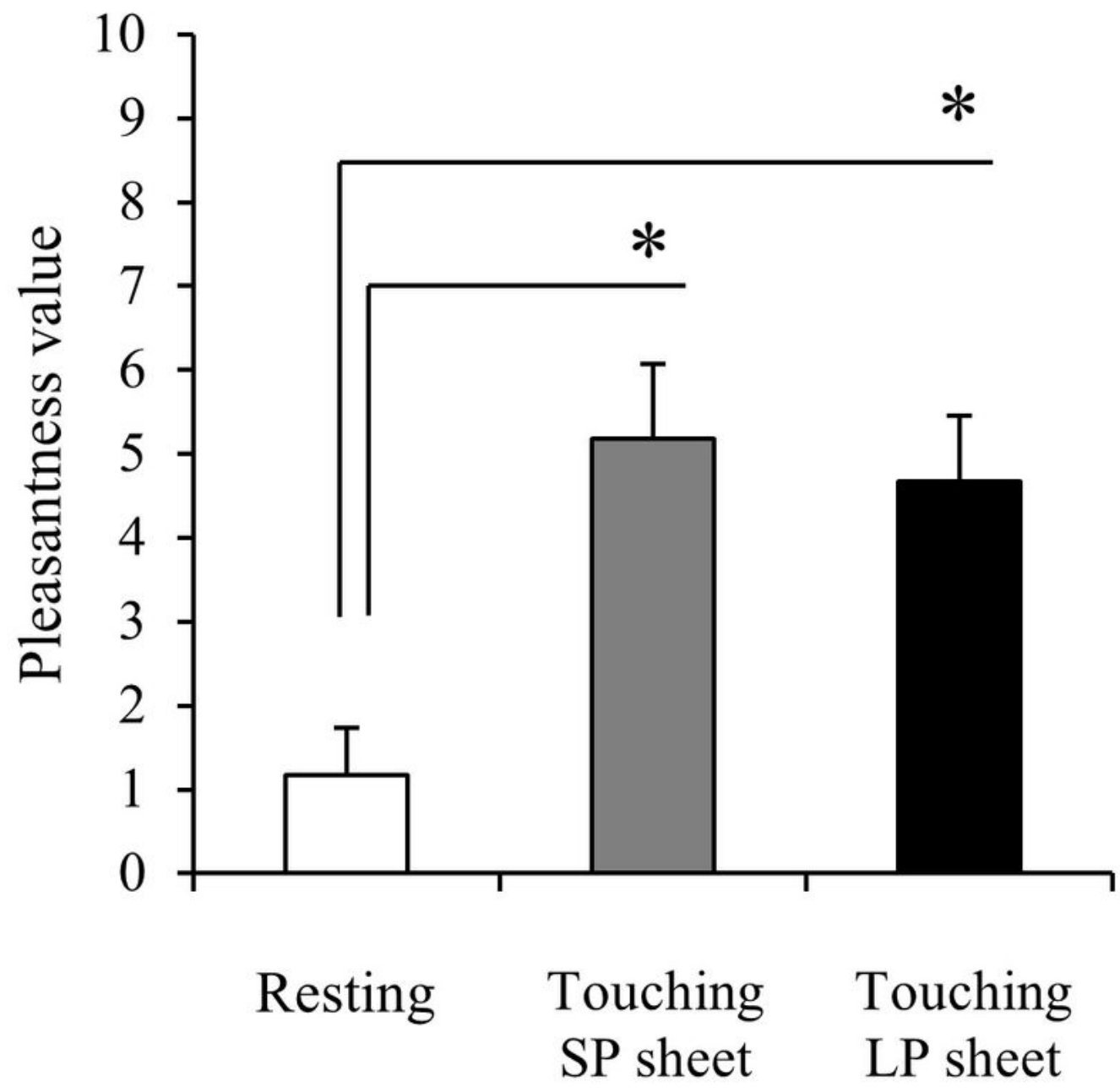

Figure 2

Perceived pleasantness values after resting and touching thesheets.All data are presented as the mean \pm standard error of the mean $(n=10)$. Perceived pleasantness was rated using a 10 -cm visual analog scale with the left end $(0 \mathrm{~cm})$ indicating "unpleasant" and the right end $(10 \mathrm{~cm})$ indicating "extremely pleasant". The data were analyzed using one-way analysis of variance with Tukey's posthoc test ( $F(1.863$, $16.77)=9.609, p<0.01$, rest: $1.17 \pm 0.56$; SP sheet: $5.18 \pm 0.90$; LP sheet: $4.67 \pm 0.78, n=10) .{ }^{*} p<0.05$ vs. 
resting state.LP sheet: diaper-like nonwoven sheet with large projections; SP sheet: diaper-like nonwoven sheet with small projections.

\section{Supplementary Files}

This is a list of supplementary files associated with this preprint. Click to download.

- Additionalfile5.pdf

- Additionalfile4.pdf

- Additionalfile3.pdf

- Additionalfile2.pdf

- Additionalfile1.pdf 